\title{
Práticas e condições de produção de leitura: percurso biográfico de estudantes de Pedagogia
}

\section{Reading practices and their production conditions: the biographical path of pedagogy students}

https://doi.org/10.34112/2317-0972a2016v34n68p29-43

\author{
Áurea Regina Guimarães Tomasi ${ }^{1}$ \\ Lúcio Alves Barros ${ }^{2}$ \\ Sara Clementina Silva ${ }^{3}$
}

RESUMO: Este texto trata de parte de uma pesquisa que teve como objetivo conhecer as práticas de leitura de estudantes de graduação em Pedagogia. Partiu-se do pressuposto de que sua familiaridade e seu traquejo com as práticas de leitura são fundamentais para a formação docente e para que, em um futuro próximo, eles possam formar leitores em suas práticas profissionais como pedagogos. Fundamentado principalmente na Sociologia da leitura, este estudo buscou conhecer as condições de produção das práticas de leitura no percurso biográfico, desde os primeiros contatos com a leitura em casa e na família, passando pelo ensino fundamental, até o curso de Pedagogia. Optou-se por uma metodologia qualitativa, entrevistando estudantes de três instituições de ensino superior. Constatou-se que os entrevistados consideram de grande importância as modificações que as práticas de leitura provocaram em suas vidas e na formação docente.

Palavras-chave: Práticas de leitura; formação de pedagogo; percurso leitura.

ABSTRACT: The following text is part of a research project aimed at knowing the reading habits of pedagogy undergraduate students. It started with the assumption that the abilities and familiarity of students with these reading practices is critical in their training

1. Universidade do Estado de Minas Gerais, Belo Horizonte, MG, Brasil.

2. Universidade do Estado de Minas Gerais, Belo Horizonte, MG, Brasil.

3. Universidade do Estado de Minas Gerais, Belo Horizonte, MG, Brasil. 
as teachers, so that in the near future these students should be able to prepare readers in their professional practices as pedagogues. Based mostly on the sociology of reading, this research sought to know the conditions of production of the reading practices of students throughout their biographical path, from their very first contacts with reading at home with their families, going through elementary school until their university course in pedagogy. We have opted for a qualitative methodology, interviewing students from three different institutions of higher education. We have found that interviewees highly consider the changes that reading practices brought to their lives and to their professional training. KEYWORDS: Reading practices; teacher training; reading habits.

\section{INTRODUÇÃO}

As práticas de leitura estão presentes em diversos espaços da vida social e se desenvolvem de diferentes maneiras, segundo os sujeitos, a época, os interesses, os lugares, entre outros aspectos que as determinam. No Brasil, a leitura é, muitas vezes, citada em pesquisas ou na mídia como pouco praticada, em decorrência, entre outros aspectos, da pouca disponibilidade de bibliotecas, do alto preço dos livros, ao lado do baixo poder aquisitivo da maior parte da população, da formação escolar e da falta de uma cultura que privilegie a leitura de textos impressos em detrimento de outras atividades.

Por outro lado, defende-se que o domínio, a prática e o traquejo dos indivíduos em relação à leitura possibilitam a formação humana no sentido da emancipação. Se a leitura, por si só, não garante o exercício da cidadania, ela, ao menos, contribui para que os indivíduos tenham mais consciência de seus direitos e deveres, a fim de que haja, ao menos potencialmente, mais criticidade e melhores condições para agir sobre a realidade na qual se vive. Um indivíduo que pratica a leitura com mais assiduidade e tem autonomia para recorrer a diversos gêneros e suportes, conforme suas inúmeras necessidades, possivelmente possui mais ferramentas para compreender o mundo que o cerca e atuar sobre ele.

Ainda que existam muitos estudos sobre as práticas de leitura em diversas áreas do conhecimento, como a Psicologia, a Pedagogia, a História, a Ciência da Informação, a Literatura ou a Sociologia da Leitura, optamos por esta última abordagem, para investigar sobre as leituras praticadas por estudantes de Pedagogia.

Considerando a importância do pedagogo como mediador na formação de crianças, adolescentes e mesmo de adultos, torna-se necessário conhecer sua visão 
e suas práticas relacionadas à leitura. É importante explorarmos um pouco mais o universo da formação de futuros educadores, no sentido de compreender que possibilidades eles poderão oferecer aos alunos como futuros leitores. Embora não seja mecânica a relação entre um educador "grande leitor" e sua atuação com os educandos nem automático o efeito da atuação do primeiro sobre estes últimos, a atitude leitora e a postura do pedagogo em relação à leitura terão influências sobre aqueles com os quais irá atuar, sejam os alunos, sejam outros professores/educadores.

Tendo como pressuposto que a prática de leitura, como nos mostra Peroni (1995), não possui uma linearidade, mas, ao contrário, pode variar conforme o momento de vida, os interesses e as circunstâncias, nos propusemos a explorar o que Bahloul (1988), ao analisar os chamados "fracos leitores", denomina de percurso biográfico. Com isso, o autor busca recuperar a recuperar a história familiar e escolar dos indivíduos em relação à leitura, ou seja, o gosto, a intensidade e as condições em que se produzem essas práticas, bem como o acesso a elas.

Dado esse referencial, a metodologia, portanto, se apoia em uma perspectiva de pesquisa qualitativa, utilizando como recurso essencial a entrevista, a fim de conhecer as histórias das práticas de leitura de estudantes de Pedagogia. Como amostra, optamos por um critério aleatório e variado, identificando, em um total de 18 indivíduos, alunos do início, do meio e do final do curso de graduação de três redes de ensino superior: federal, estadual e particular, na cidade de Belo Horizonte, Brasil.

\section{As CONDIÇÕes SOCIAIS DE ACESSO À LEITURA}

Partindo do princípio de que a leitura deve ser um direito de todos e considerando-a como objeto sociológico, ou seja, como um fenômeno produzido a partir das relações sociais, esta pesquisa buscou investigar sobre as práticas de leitura de estudantes de Pedagogia.

A Sociologia tem seu interesse voltado para diversas pesquisas relacionadas às práticas de leitura, particularmente sobre as condições de produção da leitura em diferentes espaços sociais ou em diferentes espaços escolares. Buscamos compreender por que certos indivíduos ou grupos sociais têm acesso à leitura e outros não, e como é este acesso.

Em relato sobre práticas de leitura, Bourdieu (1987, p. 132) ressalta que, antes de interrogarmos sobre o que ler, é preciso "se perguntar quais são as condições sociais de possibilidade da leitura”. Assim, é fundamental investigar e conhecer melhor 
como são construídas as práticas de leitura em diferentes meios sociais, quais são as facilidades e os obstáculos, os aspectos que favorecem e os que impedem o desenvolvimento do ato de ler, no ambiente familiar, escolar e outros.

A prática de leitura é construída socialmente e se inscreve no cultural e no social, do ponto de vista seja da produção, da edição, da distribuição de textos, de seu conteúdo, de suas finalidades, seja, ainda, de seus prolongamentos ou desdobramentos.

Dessa forma, a leitura torna-se um objeto do qual a Sociologia se apropria, pois a emancipação aportada pela leitura àqueles que a dominam e a exclusão para aqueles que não a praticam passam a constituir um aspecto a ser considerado.

Kleiman (2012, p. 47) aborda a relação das práticas de leitura com a formação humana, a emancipação e a cidadania e discute o conceito de letramento, destacando uma proposta como a da leitura crítica da realidade, defendida por Paulo Freire. E mostra que "o resgaste da cidadania, no caso dos grupos marginalizados, passa necessariamente pela transformação de práticas sociais tão excludentes com as da escola brasileira [...]". Daí a importância da formação do professor como leitor, que também deverá ser formador de outros leitores.

Em se tratando de estudantes de Pedagogia - portanto, futuros pedagogos, que, entre outras atribuições, deverão trabalhar na formação de leitores -, podemos pressupor que a leitura seja uma prática com a qual esses futuros profissionais tenham familiaridade e traquejo.

\section{A FormaÇão DE LEITORES E OS FUtURoS PEDAGogos}

Ainda que o efeito não seja mecânico, há, sem dúvida, diferentes desdobramentos na prática pedagógica de um professor ou um educador sobre a formação de uma criança ou um jovem, seja ele leitor ou não.

Assim, destaca-se a importância política de discutir as práticas de leitura de futuros pedagogos, tendo em vista que,

[...] instrumento de reprodução, mas também espaço de contradição, a leitura é, fundamentalmente, processo político. Por isso, aqueles que formam leitores - alfabetizadores, professores, bibliotecários - desempenham um papel político que poderá estar ou não comprometido com a transformação social, conforme estejam ou não conscientes da força de reprodução e, ao mesmo tempo, do espaço de contradição presente nas condições sociais da leitura, e tenham ou não assumido a luta contra aquela e a ocupação 
deste como possibilidade de conscientização e questionamento da realidade em que o leitor se insere. (SOARES, 2004, p. 28, grifos nossos).

Diversos autores mostram a importância dos professores na formação dos alunos como leitores. Hassenforder, Etevé e Lambert (1987) ressaltam o "talento" do professor para estimular os alunos. Esses autores constatam, inclusive, o interesse por determinadas obras entre estudantes que vivem em meios socioculturais que não pareciam favorecer tais escolhas.

Outro exemplo é dado por Schön (1993) sobre leituras de obras literárias por jovens alemães, cujos julgamentos positivos sobre o ensino de literatura são relacionados à pessoa do professor, enquanto os julgamentos negativos são atribuídos ao currículo.

Em pesquisa sobre formação de leitores na escola, algumas professoras foram convidadas a relatar, entre outros aspectos, os recursos em que elas se apoiam para desenvolver suas práticas de leitura em sala de aula (THOMAZI, 2005). Entre outras constatações, o resultado dessa enquete revelou que a maior parte das professoras entrevistadas atribui a seu próprio interesse, à criatividade e ao esforço pessoal a competência para desenvolver as práticas de leitura em sala de aula. É importante salientar que as entrevistadas se queixaram da falta de referências para desenvolver a tarefa de formação de leitores. Os depoimentos revelam que as professoras se sentem sem apoio e fundamentação para desenvolver suas práticas.

E os cursos de formação de professores? E os cursos de Pedagogia? De que forma os estudantes de Pedagogia são preparados para esse futuro trabalho? E eles próprios como têm se formado como leitores? Como foram suas práticas de leitura ao longo de suas trajetórias familiares e escolares?

Ou ainda:

Estamos formando um professor-sujeito, participante ativo da produção de significados sociais, aquele que pode compreender e reelaborar os processos e as razões das interlocuções? Os nossos alunos universitários e futuros professores têm tido a oportunidade de experimentar essas linguagens com a finalidade precípua de integrar-se ao mundo dos seus futuros alunos? [...] Vale dizer, o professor também deve saber ler a partir dos pressupostos da visualidade, para que, retirando dela sua força enunciativa, compreenda melhor o mundo. Essa é uma das finalidades da formação docente que 
devemos, nós professores universitários formadores de professores, imprimir ao nosso horizonte. (DAYRELL; BELMIRO, 2011, p. 186).

Investigando sobre a imagem disseminada - pela imprensa, por editores e especialistas - de que os professores não são leitores, Batista (1998) interrogou sobre as práticas de leitura de 299 docentes da rede pública de Minas Gerais. Entre outras constatações, percebeu que muitos deles, embora saibam que leituras são consideradas legítimas, não possuem a familiaridade e o traquejo que deles se esperava na lida com a literatura, porque adquiriram uma leitura "escolarizada" e não como uma herança familiar, do meio social e cultural em que vivem.

Evangelista (1998, p. 81-82) também questiona como tem sido a prática de leitura de professores no âmbito familiar ou acadêmico, tendo em vista sua formação, já que o professor é considerado como "altamente significativo no processo de socialização e de formação de crianças na qualidade de leitores”.

Se certos estudos se dedicam a investigar se os indivíduos são leitores ou não e outros se preocupam até com a classificação em "fracos" "médios" ou "fortes" leitores, há ainda aqueles que questionam o uso de critérios essencialmente quantitativos nas pesquisas. Isso porque um "fraco" leitor pode ser tanto um indivíduo cuja intensidade de leitura diminuiu como alguém que praticamente nada lia e passou a ler progressivamente.

Assim, a legitimidade da prática de leitura é vista sob outro prisma, pois:

O leitor muda e renova suas leituras ao sabor de suas experiências; abandona ou retoma a prática da leitura, modifica suas escolhas. Não-leitores podem tornar-se grandes leitores; pode-se perder ou adquirir a familiarização com o livro conforme as peripécias da vida, graças a encontros mais ou menos estimulantes; grandes leitores perdem, às vezes, sua atração pelo livro, perdem o interesse por ele. $O$ amor pela leitura se descobre ou se redescobre em diversos períodos da existência [...] (HORELLOU-LAFARGE; SEGRÉ, 2010, p. 124-125).

Entretanto, não nos interessamos apenas pelo que leem os estudantes, mas principalmente pela relação que cada um desses indivíduos estabelece com a leitura, assim como por suas trajetórias de leitores. 
Diz-se hoje que os estudantes leem pouco porque há uma crise da leitura, resultante do fato de que outros interesses substituem o interesse pelos livros. Pode ser, e não haveria que negar. Entretanto, mesmo assim, quaisquer que sejam as motivações que o conduzem à leitura, um aspecto a observar seria que ele lê porque quer encontrar nos livros respostas para questões que não formula bem ou para desenvolver uma linguagem que lhe permita exprimir pensamentos, ideias e opiniões convenientes acerca daquilo que lê ou, simplesmente, para satisfazer a sua consciência de cidadão cultivado, que exige dele que tenha lido muitos livros. (SUTTANA, 2011, p. 72).

\section{As práticas de leitura de estudantes de Pedagogia}

Procuramos, nesta pesquisa, estar atentos às modalidades de leitura declaradas pelos entrevistados. Constatamos tendência a não valorizar as leituras não legitimadas pela escola e pela crítica literária dominante. Batista (1998) e Bourdieu e Chartier (1985) alertam sobre a triagem, feita pelos entrevistados, dos títulos que merecem ser citados em uma entrevista. Esse viés também é mencionado por Chartier, Debayle e Jachimowicz (1993, p. 90).

[...] quando são interrogados sobre suas práticas, eles selecionam na memória "as verdadeiras leituras" e esquecem as outras. Entrevistas revelaram o grande número de livros lidos não indicados espontaneamente: "Evidentemente, também li romances policiais e histórias em quadrinhos, mas isso não conta", "o livro que leio todas as noites ao meu filho é um livro"? Ao tentar corrigir esses esquecimentos, quando possível, chegam a dobrar o número de livros lidos por mês, de 2,5 para mais de cinco!

Esse cuidado nos fez incluir, no roteiro de entrevistas, perguntas sobre as práticas de leitura em um sentido mais amplo, contemplando a diversidade de suportes e as influências que cada estudante recebeu em seu percurso biográfico de leitor, desde a família, passando pela escola, no ensino fundamental e médio, até chegar ao ensino superior. Entretanto, aqui apresentamos apenas algumas constatações sobre os dois extremos: as leituras na infância com a família e as leituras atuais - de entretenimento e acadêmicas - durante o curso de Pedagogia.

Os estudantes entrevistados são predominantemente do sexo feminino; há apenas quatro do sexo masculino. Mais da metade é de solteiros, que vivem com os pais em casa própria e possuem renda mensal familiar entre três e nove salários 
mínimos. No momento da realização da pesquisa, oito dos 18 entrevistados trabalhavam em ocupações próprias de estudantes, na "Escola Integrada", como bolsista, ou em laboratório de pesquisa, biblioteca, monitoria e tutoria "Jovem do futuro".

O perfil desses estudantes de Pedagogia mostra interesse por outras práticas culturais, além da leitura: televisão, predominando os filmes e os noticiários, seguidos de novela e esporte. Assistem também a documentários, dança, entrevista, programas de variedades, humor, religiosos e desenho animado. Apenas um terço desses estudantes vai ao cinema com frequência, e teatro e museus são bem pouco, ou raramente, frequentados por todos. A prática de esportes está presente no cotidiano de apenas dois entrevistados. Citaram, ainda, como ocupações nas horas livres: relacionamento com amigos, família e namorado: e mencionaram ouvir música, ir à igreja e curtir a natureza.

Ao investigarmos como foi o início do percurso biográfico na formação do leitor, consideramos a importância do contexto, inclusive das primeiras práticas de leitura no meio familiar (DELLISA; LAPLANE, 2012). Constatamos que, na época em que esses estudantes eram crianças e iniciavam sua incursão no mundo letrado, a maior parte dos pais e mães dos entrevistados não possuía grande familiaridade com a leitura. Foi possível notar que não há distinção entre as práticas de leitura dos pais dos estudantes das três redes de ensino - privada, estadual ou federal. Da mesma forma, não encontramos diferenças entre as práticas de leitura de pais e de mães, o que parece ser coerente com os dados sobre escolaridade, que igualmente não se distinguiu nesse grupo pesquisado.

A análise das entrevistas nos mostra que pais e mães não liam ou liam muito pouco ou raramente, e um entrevistado declarou que a mãe era analfabeta. Os que liam alguma coisa citaram, em primeiro lugar, leituras religiosas como a Bíblia; em segundo, jornal e histórias em quadrinhos. Vale ressaltar que, nesse caso, as histórias em quadrinhos eram lidas pelos pais para eles próprios, ainda que elas pudessem ser lidas algumas vezes em voz alta para os filhos. Indicaram ainda leituras de autoajuda, bulas, receitas e revistas.

As leituras que os pais - mesmo aqueles que não se interessavam pela leitura praticavam para esses estudantes quando eram pequenos revelam um pouco mais de investimento. Notadamente as mães se mobilizavam em torno dessa atividade. Entretanto, parece que a cobrança dos estudos era feita, como no caso de um pai que não lia, mas "xingava" quando o filho não estudava, ou daqueles que repetiam: "quem não lê e [não] estuda muito, não consegue nada na vida". Foram mencionados 
ainda aqueles que, mesmo com sacrifício, incentivavam os filhos a ler, comprando livros, revistinhas e até dicionário ou coleções de livros.

As práticas de leitura referidas no ensino fundamental e médio foram bastante variadas e, embora não sejam objeto deste artigo, cabe assinalar que, conforme declararam os estudantes entrevistados, elas dependiam, em boa medida, dos diferentes professores, independentemente da escola, da biblioteca ou da rede de ensino. Assim, algumas práticas de leitura escolares passaram despercebidas pelos alunos, outras eram desagradáveis e outras deixaram marcas bem positivas, despertando mesmo o gosto e o prazer pela leitura. Essa circunstância no percurso de leitor foi citada por muitos entrevistados, o que nos leva a atribuir à influência do professor um peso maior que à personalidade ou habilidade do aluno, como já mencionado (HASSENFORDER; ETEVÉ; LAMBERT, 1987; SCHÖN, 1993).

$\mathrm{E}$ as leituras no ensino superior? Que contribuições a formação docente em Pedagogia tem trazido para os futuros educadores como leitores?

Também a respeito das leituras praticadas na faculdade, não constatamos diferenças marcantes entre os relatos dos estudantes das três redes. A maior parte declarou ler tudo o que os professores indicam para as aulas, para a realização de trabalhos, pesquisa - enfim, tudo o que é obrigatório. No entanto, uma entrevistada se queixou dessa obrigatoriedade: "[...] estou lendo Paulo Freire, mas é tão obrigatório que tira o prazer". Alguns, notadamente da rede estadual, ressaltaram ler além do que é solicitado ou exigido pelos professores. O conteúdo lido é essencialmente "teórico", voltado para as ciências sociais, como Filosofia, Sociologia e Metodologia Científica, além de temas inerentes à Pedagogia e à Educação. E a finalidade dessas leituras é ilustrada pelas palavras de uma estudante: "tudo para desenvolver a capacidade crítica".

Os professores tendem a se limitar às leituras específicas de cada disciplina, mas alguns poucos indicam leituras complementares, extras, referentes a outros conteúdos. Há também pouca indicação de títulos de literatura ou de vídeos. Apenas uma professora da Universidade Federal foi citada como assídua indicadora do gênero literário, de filmes e museus.

Nem todos determinaram a quantidade de suas leituras, o número de horas ou de páginas, mas nenhum disse ler pouco, e alguns destacaram ler intensamente ou em "quantidade impressionante". A maior parte dos entrevistados utiliza, como suporte, textos "xerocados", e um terço revelou usar mais fotocópias que livros ou periódicos. 
E, quando perguntados sobre as modificações que as práticas de leitura na faculdade provocaram em suas vidas, as respostas dessa amostra foram todas no mesmo sentido dos seguintes depoimentos:

A leitura nos possibilita ter outro olhar sobre o mundo, inclusive sobre nossas próprias práticas de leitura.

Sem dúvida, depois de ler Freud minha vida nunca mais foi a mesma. Os teóricos da educação mudaram minha forma de enxergar o mundo e entender as relações humanas. Foram incontáveis paradigmas quebrados.

As leituras da faculdade ampliaram minha visão em relação a tudo ou quase tudo que conheço. Agora enxergo situações não explícitas que interferem na vida. Sou mais crítico e analítico.

A leitura modifica nossa vida, modificou minha vida. Mais ainda, depois da faculdade tenho outra visão. Tenho senso crítico. (Dados da pesquisa)

Apesar de as leituras acadêmicas tomarem bastante tempo dos estudantes e de uma aluna ter confessado certo sentimento de culpa quando lê algo que não seja para as aulas da universidade, os entrevistados declararam encontrar algum tempo para outras leituras além das acadêmicas.

Bourdieu (1985) nos alerta para o fato de que, ao ser perguntado sobre o que lê, em geral o entrevistado seleciona o que acredita necessário declarar. Chartier, Debayle e Jachimowicz (1993) e Chartier (2005) nos mostram que o entrevistado, quando não tem tempo para refletir sobre a pergunta, nem sempre se lembra das leituras feitas, nem, tampouco, dos títulos ou dos autores. Tendo em conta essas duas ponderações, a pesquisa desviou o foco desses aspectos e voltou-se principalmente para as preferências dos leitores, deixando-os à vontade para citar títulos e autores, o que resultou bastante significativo.

No que se refere à leitura de livros, houve certa distinção entre o público das três redes: destacaram-se entre os entrevistados da faculdade privada as leituras de livros espíritas e best sellers, enquanto os da Universidade Federal reportaram mais a literatura infantil como uma forma de entretenimento e, ao mesmo tempo, 
preparação para o trabalho; e os da Universidade Estadual citaram predominantemente romances e poesia.

Em relação a outros textos escritos, dois terços dos estudantes entrevistados declararam ler revistas e destacaram, em primeiro lugar, de forma mais significativa, as de informação, seguidas daquelas relacionadas à educação, à divulgação científica e, em número bem menor, as revistas femininas. Apenas a metade desses estudantes disse que lê jornal. Em ambos os casos, nenhum declarou comprar ou muito menos assinar revistas e jornais. $\mathrm{O}$ acesso se dá sempre em uma biblioteca, no trabalho, com vizinhos ou amigos.

Mas os estudantes foram quase unânimes em declarar que estão satisfeitos do ponto de vista da qualidade de suas leituras. Já no aspecto quantitativo, com exceção de um, os demais disseram que gostariam de ter mais tempo para ler:

Estou satisfeita, mas acredito que posso ler mais... gostaria de ter mais tempo para dedicar-me à leitura.

Não estou satisfeito com a quantidade. Com relação à qualidade, estou satisfeito. Não tenho muito tempo para ler outros títulos que me interessam.

Estou satisfeito com a qualidade. Tá ótimo. Leio de tudo um pouco. Mas queria ter mais tempo para ler mais.

Depois dos livros da faculdade só sobra tempo para ler duas a três páginas de leitura do meu interesse pessoal.

Estou satisfeita com o que li até agora, mas sinto que preciso de mais, muito mais, pelo menos três vezes mais do que faço atualmente... gostaria de estabelecer uma rotina diária.

Gostaria de ler mais. Tenho acesso, mas não tenho tempo (dados da pesquisa, grifos nossos).

Essa nítida vontade de ter mais tempo para ler é coerente com a importância que os futuros pedagogos atribuem à prática da leitura: 
Uma forma de penetrar em outros universos, sem sair do seu...

Conhecimento. Leitura é conhecimento. É abrir a visão de mundo, de tudo.

É possibilitar a criação de novas ideias.

É ter a oportunidade de acesso a outras informações ao que os outros autores dizem.

Viajar sem sair de casa, usando apenas a imaginação.

A leitura é uma forma de compreender o mundo no qual vivemos.

Leitura é um meio de informação, de obter cultura.

Leitura é prazer.

Leitura é viver.

Leitura é tudo. (Dados da pesquisa)

Percebemos nessas declarações que os estudantes valorizam a leitura pelos desdobramentos que ela lhes proporciona. A noção de prazer, de conhecimento e de amplitude da visão e compreensão do mundo parece tê-los conquistado e comprovado para esses futuros pedagogos que ler não é simplesmente algo necessário, como o discurso escolar sempre repete, mas algo fundamental em suas vidas, independentemente da profissão.

\section{CONSIDERAÇÕES FINAis}

Apesar do pouco contato com a leitura na infância, vivida em um ambiente pouco letrado e das limitações da prática de leitura universitária, que é focada principalmente nos textos teóricos, os depoimentos sobre os desdobramentos das práticas de leitura desenvolvidas, ainda que tardiamente, indicaram com unanimidade que esses estudantes percebem e valorizam a importância da leitura em sua formação docente. 
Embora não tenham sido discutidos neste texto, os demais dados levantados nas entrevistas e, em especial, os depoimentos sobre a importância da leitura nos revelaram que, ainda que a dedicação à leitura literária varie entre esses estudantes de Pedagogia, os futuros pedagogos valorizam a leitura como prazer, entretenimento e instrumento de construção do saber.

Entretanto, dado o limite do tempo, absorvido em grande parte pelas leituras técnicas e teóricas, o desafio reside em conciliar a prática de leitura voltada mais especificamente para a formação e para o trabalho docente com a prática de leitura para atender ao interesse pessoal, ao enriquecimento cultural e, mesmo, para o entretenimento, igualmente importantes para a formação docente e para a formação de alunos e leitores com os quais esses futuros professores irão se relacionar e os quais se propõem a educar e a formar.

Cabe interrogar sobre a formação dos cursos de Pedagogia e suas propostas em relação à formação de leitores. Os currículos voltados para esse objetivo têm como preocupação a formação de professores que irão formar futuros leitores? Que concepções de leitura esses currículos possuem? Privilegiam apenas a leitura técnica ou guardam espaço e tempo para a literatura em geral, incluindo a literatura infantil? $\mathrm{E}$ os professores dos cursos de Pedagogia são leitores? Compartilham suas próprias leituras com seus alunos futuros pedagogos?

Resta, finalmente, propor e possibilitar que os estudantes de Pedagogia tenham acesso, independentemente da imposição da matriz curricular, a mais diversidade de textos e suportes de todos os tipos. A indicação de uma leitura interessante, instigante ou apaixonante, feita por um professor ou um colega, pode surtir grande efeito de contágio. O relato dos estudantes desta pesquisa revela que a oportunidade é capaz de contribuir para a formação do leitor.

$\mathrm{O}$ acesso a uma grande variedade de formas de leitura: textos ou imagens, livros, revistas, jornais, cinema, museus, bibliotecas, internet, enfim, nos diversos meios e suportes, pode possibilitar ao futuro pedagogo gostar de ler, interessar-se pela leitura e sentir-se capaz e autônomo como leitor. Isso pode não garantir a multiplicação da formação de novos leitores, mas terá grandes chances de favorecê-la.

\section{REFERÊNCIAS}

BAHLOUL, J. Lectures précaires, étude sociologique sur les faibles lecteurs. Paris: Service des etudes et de la recherche, BPI Centre George Pompidou, 1988. 
Práticas e condições de produção de leitura: percurso biográfico de estudantes de Pedagogia

BATISTA, A. A. G. A leitura incerta: a relação de professores (as) de português com a leitura. Educação em Revista, Belo Horizonte: Autêntica, 1998.

BOURDIEU, P. Lectures, lecteurs, lettrés et littérature. In: BOURDIEU, P. Choses dites. Paris: Minuit, 1987.

BOURDIEU, P.; CHARTIER, R. La lecture: une pratique culturelle. In: CHARTIER, R. Pratiques de la lecture. Paris: Rivages, 1985. p. 223.

CHARTIER, A.-M. Os futuros professores e a leitura. In: GALVÃO, A. M. O.; BATISTA, A. A. G. (Org.). Leitura: práticas, impressos, letramentos. Belo Horizonte: Autêntica, 2005. p. 89-97. (Coleção Linguagem e Educação).

CHARTIER, A.-M.; DEBAYLE, J.; JACHIMOWICZ, M.-P. Lectures pratiqués et lectures déclarées réflexions autour d'une enquête sur les lectures d'étudiants en IUFM. In: FRAISSE, E. (Dir.). Les étudiants et la lecture. Paris: PUF, 1993. p. 73-98.

DAYRELL, M.; BELMIRO, C. A. Formação de professores e os desafios contemporâneos dos livros de literatura. In: MARTINS, A. A. et al. (Org.). Livros e telas. Belo Horizonte: Editora UFMG, 2011. p. 175-187.

DELLISA, P. R.; LAPLANE, A. L. F. Práticas de leitura na família e na escola. Leitura: Teoria e Prática, Campinas, v. 30, n. 58, 2012.

EVANGELISTA, A. A. M. A leitura literária e os professores: condições de formação e de atuação. In: MARINHO, M.; SILVA, C. S. R. (Org.). Leituras do professor. Campinas: Mercado de Letras, 1998. HASSENFORDER, J.; ETEVÉ, C. ; LAMBERT, O. Role du college dans le développement des lectures de l'enfant à l'adolescent. Inter CDI, Paris, n. 90, p. 20-35, 1987.

HORELLOU-LAFARGE, C.; SEGRÉ, M. Sociologia da leitura. Cotia, SP: Ateliê Editorial, 2010.

KLEIMAN, A. (Org.). Os significados do letramento. Uma nova perspectiva sobre a prática social da escrita. 2. ed. Campinas, SP: Mercado de Letras, 2012.

PERONI, M. Histoires de lire. Paris: Bibliothèque publique d'information. Centre Georges Pompidou, 1995.

SCHÖN, E. La fabrication du lecteur. In: CHAUDRON, M.; SINGLY, F. Identité lecture ecriture. Paris: Centre Georges Pompidou; BPI, 1993.

SOARES, M. B. As condições sociais da leitura: uma reflexão em contraponto. In: ZILBERMAN, R.; SILVA, E. T. (Org.) Leitura: perspectivas interdisciplinares. São Paulo: Ática, 2004.

SUTTANA, R. Um problema de formação: reflexões sobre literatura, leitura e ensino. Leitura: Teoria e Prática, Campinas, v. 29, n. 57, p. 66-77, 2011.

THOMAZI, A. R. G. L'enseignant de l'école élémentaire et le curriculum de la lecture. Enquête à Belo Horizonte, Brésil. Tese (Doutorado) - Ciências da Educação, Université Paris V, Paris, 2005.

\section{SOBRE OS AUTORES}

Áurea Regina Guimarães Tomasi tem Graduação em Ciências Sociais (Universidade Federal de Minas Gerais), Pós-Graduação em Ciências Sociais Aplicadas à Educação (Universidade Federal de Minas Gerais), Mestrado e 
Doutorado em Ciências da Educação (Université René Descartes, França). Atualmente é Professora na Faculdade de Educação da Universidade do Estado de Minas Gerais (UEMG) e do Programa de Pós-Graduação em Gestão Social Educação e Desenvolvimento Local do Centro Universitário UNA.

E-mail: aureagt@gmail.com

Lúcio Alves Barros tem Graduação em Ciências Sociais (Universidade Federal de Juiz de Fora), Mestrado em Sociologia e Doutorado em Ciências Humanas (Universidade Federal de Minas Gerais). Atualmente é professor e vice-diretor da Faculdade de Educação da Universidade do Estado de Minas Gerais (UEMG). E-mail: luciobarros46o@gmail.com

Sara Clementina Silva tem Graduação em Pedagogia (Universidade do Estado de Minas Gerais), Especialização em Psicopedagogia (Universidade Castelo Branco), Mestrado em Educação (Universidade do Estado de Minas Gerais). Atualmente é professora aposentada da Universidade do Estado de Minas Gerais (UEMG). E-mail: sarasilva2311@hotmail.com

Recebido em 10 de outubro de 2015 e aprovado em 14 de fevereiro de 2016. 